\title{
Thermal proteome profiling: unbiased assessment of protein state through heat-induced stability changes
}

\author{
André Mateus, Tomi A. Määttä and Mikhail M. Savitski
}

\begin{abstract}
In recent years, phenotypic-based screens have become increasingly popular in drug discovery. A major challenge of this approach is that it does not provide information about the mechanism of action of the hits. This has led to the development of multiple strategies for target deconvolution. Thermal proteome profiling (TPP) allows for an unbiased search of drug targets and can be applied in living cells without requiring compound labeling. TPP is based on the principle that proteins become more resistant to heat-induced unfolding when complexed with a ligand, e.g., the hit compound from a phenotypic screen. The melting proteome is also sensitive to other intracellular events, such as levels of metabolites, post-translational modifications and protein-protein interactions. In this review, we describe the principles of this approach, review the method and its developments, and discuss its current and future applications. While proteomics has generally focused on measuring relative protein concentrations, TPP provides a novel approach to gather complementary information on protein stability not present in expression datasets. Therefore, this strategy has great potential not only for drug discovery, but also for answering fundamental biological questions.
\end{abstract}

Keywords: Thermal proteome profiling, Protein thermal stability, Drug discovery, Target deconvolution, Mass spectrometry-based proteomics, Tandem mass tags

\section{Background}

Current drug discovery generally starts by using a targetor a phenotypic-based approach for compound screening [1]. In the former, a particular protein with an altered function or expression in a disease is targeted. This approach facilitates compound optimization, since structureactivity relationships are generally easy to establish [2]. However, disease-specific proteins are difficult to find and not all of them are 'druggable'-the currently approved drugs only target around 900 proteins (including around 200 pathogen proteins) [3]. Further, the cellular context (i.e., subcellular location, post-translational modifications, levels of metabolites, and interactions with other proteins) is important for the function of proteins and is lost when working with purified proteins. These limitations have led, in recent years, to an renewed interest in phenotypic screening [4-6]. In this strategy, a particular trait or phenotype is sought in live cells (e.g., induction of cell

* Correspondence: mikhail.savitski@embl.de

European Molecular Biology Laboratory, Genome Biology Unit, Meyerhofstr. 1, 69117 Heidelberg, Germany death in cancer cells). The major challenge of phenotypic screening is the deconvolution of the mechanism of action of the putative drug molecules discovered during the screen. For that reason, multiple new methodologies for target identification have sprouted and have been extensively reviewed $[7,8]$.

A number of strategies use mass spectrometry-based proteomics $[9,10]$ and are based on changes in target stability upon compound binding. These include, for example, drug affinity responsive target stability (DARTS) [11], stability of proteins from rates of oxidation (SPROX) [12-14], or thermal proteome profiling (TPP) [15-18]. DARTS is based on limited proteolysis (LiP) [19], in which a low concentration of a protease with broad specificity is used to cleave only exposed regions of a protein (generally, loops or unfolded regions). DARTS exploits the fact that ligand binding can protect some of these regions from proteolysis [11]. In SPROX, aliquots of proteins are subjected to an increasing concentration of a chemical denaturant followed by oxidation of methionines that become exposed after 
unfolding [12-14]. Binding of a ligand stabilizes proteins against chemical denaturation. TPP exploits the differential stability of proteins after heat stress, i.e., proteins become more resistant to heat-induced unfolding when complexed with a ligand [15-18]. TPP can be applied in live cells, does not require compound labeling, and allows for an unbiased search of drug targets-to date, the only approach that combines all of these advantages. This review focuses on the principles of TPP, the recent advances in the method, and its possible future applications.

\section{From thermal shift assays to thermal proteome profiling}

When proteins are subjected to a thermal stress, they generally irreversibly unfold, expose their hydrophobic core and subsequently aggregate (Fig. 1) [20, 21]. The temperature at which unfolding happens (the apparent melting temperature, $T_{m}$ ) can be increased by the presence of a ligand, since part of the energy provided to the protein-ligand system is then used to dissociate the ligand from the protein (Fig. 1) [22-24]. This stabilization has been explored in purified proteins in structural biology $[25,26]$ and in drug discovery [27, 28]. The realization that this stabilization could be achieved directly in a cellular context [21] led to the development of the cellular thermal shift assay (CETSA) [29, 30]. For the first time, CETSA allowed the study of target engagement in cells and tissues. An advantage of using live cells is the possibility of monitoring the mechanisms of import and activation of pro-drugs. For example, methotrexate seems to be activated through polyglutamation prior to engagement of its target proteins dihydrofolate reductase (DHFR) and thymidylate synthase (TS) - inhibition of polyglutamate synthetase strongly decreased the stabilization of these targets by methotrexate [29]. While the initial CETSA protocol was based on immunoblot detection, microtiter-based formats have since been developed [30, 31]. This allowed the screen of intracellular target engagement of thousands of compounds and led to

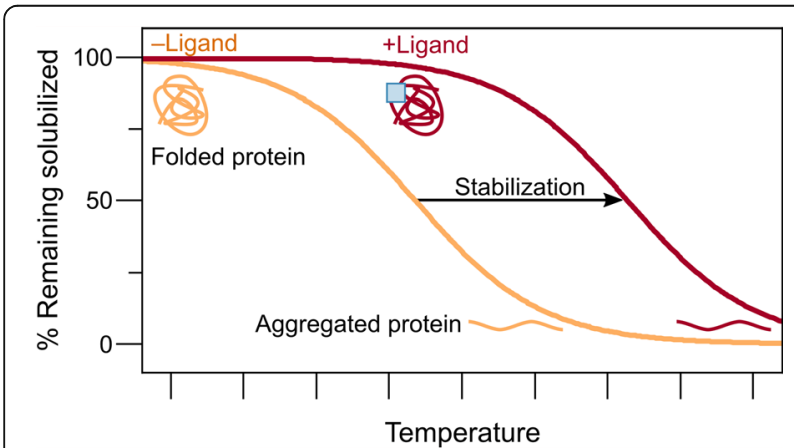

Fig. 1 Principle of thermal shift assays. Proteins can be thermally stabilized by the presence of a ligand, leading to a higher apparent melting temperature $\left(T_{m}\right)$ the discovery of a promising novel inhibitor of thymidylate synthase, CBK115334 [31]. However, since CETSA is based on an antibody readout, it is limited to the study of only a small number of proteins simultaneously. To allow proteome-wide studies of drug-protein interactions in a single experiment, the CETSA principles were combined with mass spectrometry-based proteomics $[9,32]$ in the thermal proteome profiling (TPP) approach [15-18]. This approach allows the unbiased search of direct targets and off-targets of drugs, as well as their indirect downstream effects on biochemical pathways (as discussed later).

\section{Thermal proteome profiling method}

Since its original publication [15], the TPP method has been modified and expanded to tackle different challenges [15-18, 33-36]. However, the general outline of the procedure remains similar and can be described as: (1) preparation of cells for the experiment, (2) drug treatment, (3) heating procedure, (4) extraction of soluble protein fraction, (5) protein digestion and peptide labeling with tandem mass tags [37, 38], (6) mass spectrometric analysis, and (7) data processing (Fig. 2). These steps are described in more detail in the following sections.

\section{Preparation of the cells for the experiment: cell extracts vs. intact cells to distinguish direct and indirect targets} TPP can be performed on cell extracts, intact cells, or tissues. By lysing the cells prior to TPP, proteins, metabolites and co-factors are diluted. This should largely stop the normal metabolism of the cell and, therefore, stabilization of proteins will only be caused by the drug treatment (in other words, only direct targets will be identified). Conversely, in intact cell experiments, the cellular machinery is active and it is possible to observe not only the stabilization of the proteins to which the drug binds directly, but also the stabilization of downstream proteins resulting from the (in)activation or conformational change of the direct target. For example, in cell extracts, TH1579 only stabilized 7,8-dihydro-8-oxoguanine triphosphatase (MTH1), its known target [35]. However, in intact cells, the same compound also stabilized deoxycytidine kinase (dCK), an enzyme that recycles deoxynucleosides from degraded DNA-by catalyzing the phosphorylation of deoxycytidine, deoxyguanosine and deoxyadenosine [39]. Since MTH1 inhibition promotes DNA damage [40], this suggests that the pool of deoxynucleosides is increased and contributes to dCK stabilization.

\section{Drug treatment and heating procedure: single drug concentration vs. concentration range}

After their preparation, the cells are incubated with the drug. At this step, either a single compound concentration 


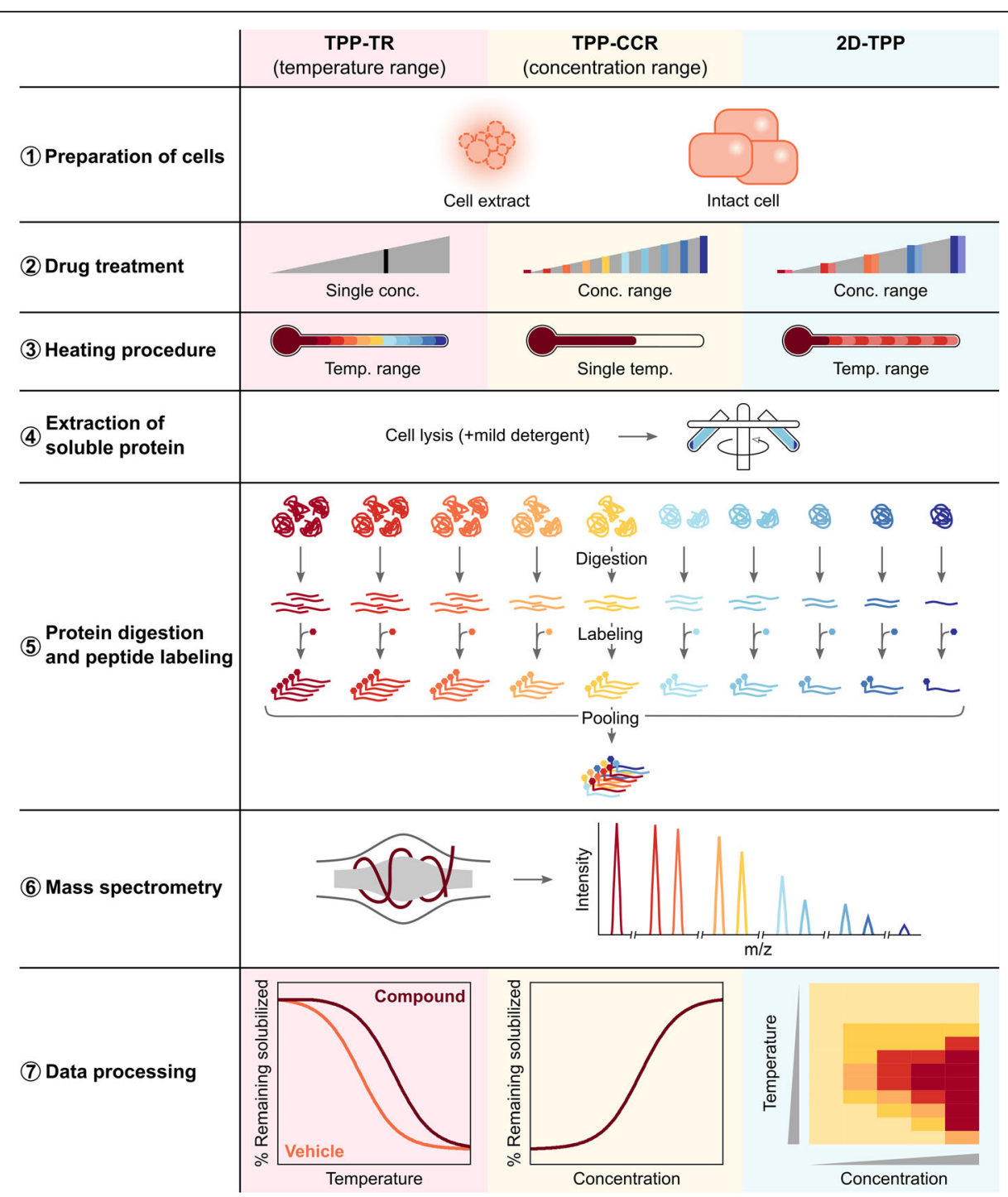

Fig. 2 Thermal proteome profiling (TPP) method can be performed in one of three modes: temperature range (TPP-TR); compound concentration range (TPP-CCR); or two-dimensional TPP (2D-TPP). The general procedure is composed of (1) preparation of cells for the experiment, in which either cell extracts are prepared or intact cells are cultured; (2) drug treatment with either a single compound concentration (TPP-TR) or a range of compound concentrations (TPP-CCR and 2D-TPP); (3) heating the cells to a range of temperatures (TPP-TR and 2D-TPP) or a single temperature (TPP-CCR); (4) extraction of soluble protein fraction using ultracentrifugation after cell lysis - a mild detergent can be included to solubilize membrane proteins; (5) protein digestion using a proteolytic enzyme followed by peptide labeling with neutron-encoded isobaric tags (at this step, the illustration shows an example of the procedure for a TPP-TR experiment, but an analogous labeling scheme is used for TPP-CCR or 2D-TPP_-see details in the main text); (6) mass spectrometric analysis using an Orbitrap mass spectrometer to resolve the $6 \mathrm{mDa}$ differences between some of the adjacent TMT reporter ions (again, at this step, the illustration shows an example of the resulting spectra of one peptide following a TPP-TR experiment); and (7) data processing to obtain plots like the ones illustrated: for TPP-TR, melting curves for each protein in the absence of presence of drug will be generated — target engagement is observed as a shift in the apparent melting temperature $\left(T_{m}\right)$ of the protein; for TPP-CCR, potency curves for each protein will be obtained-from these curves it is possible to estimate the potency of the drug against each of the targets; for 2D-TPP, heat maps colored by the intensity of the abundance of soluble protein at each concentration and temperature will be generated

is compared with a control, or a range of compound concentrations is applied. Generally, this choice is directly linked with the next step of the protocol-the heating procedure.

When a single compound concentration is used, the cells are heated up to a range of temperatures, and this experiment is termed temperature range TPP (TPP-TR). With this approach, it is possible to identify the majority of the targets of a compound, e.g., 49 of the 66 kinases that staurosporine inhibits, and that could be detected in $\mathrm{K} 562$ cell extracts, showed a reproducible shift in $\mathrm{T}_{\mathrm{m}}$ of more than $1{ }^{\circ} \mathrm{C}$ [15]. However, there was a poor 
correlation between the magnitude of the $T_{m}$ shift and the affinity of staurosporine to each kinase. This is because the extent of thermal stabilization depends not only on the affinity of the ligand, but also on the melting thermodynamics of the native protein.

To obtain affinity estimates with TPP, a compound concentration range TPP (TPP-CCR) can be performed. In TPP-CCR, cells are incubated with a range of concentrations of compound and heated to a single temperature. For example, K562 cell extracts incubated with a range of concentrations of GSK3182571 and heated to $53{ }^{\circ} \mathrm{C}$ showed a good agreement between the affinity determined in TPP-CCR and in kinobeads competition-binding experiments [15].

Recently, Becher et al. [18] developed a two-dimensional TPP (2D-TPP), in which cells are incubated with a range of compound concentrations and heated to multiple temperatures. This expansion allows an immediate estimate of compound affinity to the target and is much more sensitive at identifying targets. In one example, phenylalanine hydroxylase (PAH) was identified as an off-target of the histone deacetylase (HDAC) inhibitor panobinostat [18], which had not been possible with TPP-TR [16]. The reason for the substantial gain in sensitivity is that untreated and treated conditions are compared in the same mass spectrometry experiment, which yields more precise quantification (contrary to when two distinct experiments are compared, as is the case with TPP-TR). Further, in the 2DTPP approach, the protein is expected to be stabilized in a dose-dependent manner, which adds an additional quality requirement to the data and filters out false positives [18].

\section{Extraction of soluble protein fraction}

Following the heat treatment, the cells are lysed and proteins that have denaturated and aggregated are removed using ultracentrifugation. In the original protocol [15], membrane proteins were not analyzed, since all insoluble proteins were removed at this step. However, follow-up studies have shown that mild detergents can be used to include these proteins in the analysis without affecting heat-induced aggregation or promoting resolubilization of precipitated proteins [17, 33]. For example, the use of NP40 detergent did not affect the $T_{m}$ values of proteins in Jurkat cells [17]. However, it allowed the identification of membrane proteins, such as tyrosine phosphatase CD45 (PTPRC) as well as other proteins of the $\mathrm{T}$ cell receptor (TCR) pathway, as the targets of pervanadate.

\section{Protein digestion and peptide labeling with isobaric tags}

Once the soluble proteins are collected, they are digested using a general proteomics workflow (e.g., ingel digestion [15-18], or in-solution digestion [33, 35]). The resulting peptides from each condition are then labeled using isobaric tandem mass tags (TMT) [41] and combined into a single sample to be analyzed by mass spectrometry. These tags, which when intact have the same mass, can be fragmented and yield reporter ions of different masses. This enables a quantitative comparison of multiple experimental conditions in the same mass spectrometry run. The recent expansion of TMT based quantification at first to eight $[37,42]$ and subsequently to ten conditions [38] was instrumental for the successful implementation of TPP. Particularly, in a TPP-TR experiment, the peptides from each temperature are labelled with a unique label, which allows the simultaneous quantification of the amount of soluble proteins at the different temperature conditions. This was key for the throughput and precision of the experiments. In a TPP-CCR experiment, each concentration condition is instead labelled with a unique label. To reduce the analysis time of a 2D-TPP experiment, while still having a reasonable resolution for compound concentration, five concentrations of compound are used at each temperature level [18]. In this way, peptides from each concentration of two adjacent temperatures are labelled with a unique tag from the same TMT10 set.

\section{Mass spectrometric analysis and data processing}

So far only Orbitrap instrumentation [43] permits the analysis of neutron-encoded TMT10 tags, due to their capability to properly resolve the $6 \mathrm{mDa}$ differences between some of the proximate TMT reporter ions. Following mass spectrometric analysis, protein identification and quantification is performed. For this purpose, a Python package (isobarQuant [44]) has been developed to be used together with the Mascot search engine (from Matrix Science [45]). While isobarQuant was specifically developed to address isobaric mass tag based quantification, other analysis platforms can also be used for this step, such as MaxQuant [46, 47] or ProteomeDiscoverer (Thermo Scientific). The analysis of the protein quantification data is then performed with the Bioconductor [48] TPP package [49], which also allows the analysis of 2D-TPP data. This package includes a statistical analysis step that highlights all the significant targets of a treatment.

\section{Future perspectives}

TPP was initially developed for the identification of compound targets and off-targets. In this regard, it was introduced as a new strategy to discover novel drug targets (for instance that brusatol is an inhibitor of global protein synthesis [34]), and off-targets that explain some of the adverse effects (e.g., alectinib and vemurafenib bind ferrochelatase $(\mathrm{FECH})$, suggesting why they induce photosensitivity [15]). In addition, some of the new offtargets could potentially be used for drug repurposing 
(as an example, panobinostat binds and inhibits $\mathrm{PAH}$, which might be used in tyrosinemia [18]) (Fig. 3). In the future, this approach could be pushed further, for example to find new antibiotic targets. Target identification by ligand stabilization (TILS), a technique based on similar principles to TPP, has recently shown that this method can be applied to bacteria and is not restricted to mammalian cells [50]. TILS relies on the analysis of the precipitate, rather than the remaining soluble fraction, and uses dimethyl labeling for protein quantification.

In principle, the thermal stability of any protein is affected by ligand binding to some extent. However, some target proteins show no statistically significant shifts in apparent melting temperature. For example, dasatinib did not show stabilization of its known target, BCR-ABL, despite the appearance of downstream targetrelated effects [15]. Also, some very low abundant proteins will not be identified by mass spectrometry, hence their stability will not be measured. Further, changes in stability of multi-domain proteins, for which only one domain is involved in ligand binding, will depend on the impact of the change in the whole protein (since protein denaturation and aggregation happens for the full-length polypeptide). Future improvement in instrumentation

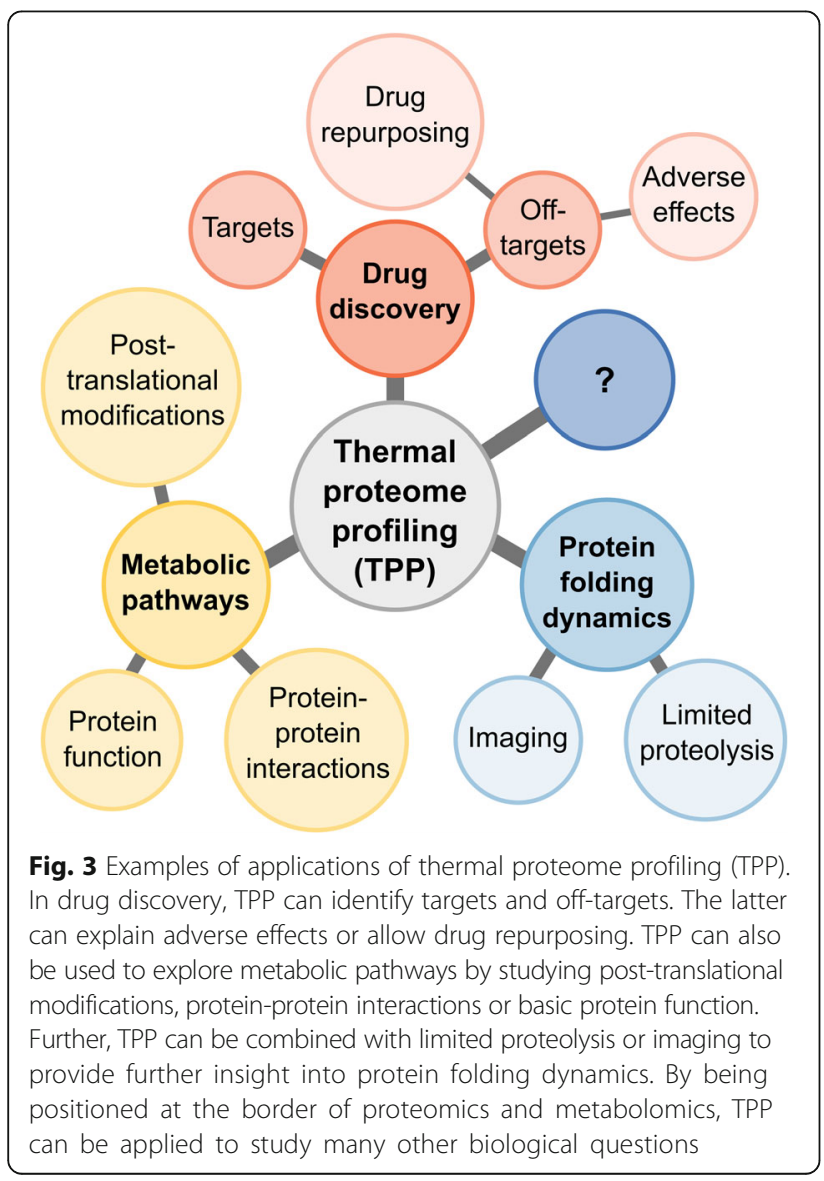

and sample preparation will lead to increased proteome coverage and enable identification of more low abundant targets (including cell surface proteins [51]), while newer TPP formats (2D-TPP) will help to identify even small stability shifts (as was seen with panobinostat and $\mathrm{PAH}$ stabilization [18]).

Besides drug discovery, TPP might become an important tool to map metabolic pathways, since it allows the study of post-translational modifications, protein-protein interactions, and the basic function of proteins (Fig. 3). For the study of post-translational modifications, it has been shown that phosphorylation affects protein thermal stability (e.g., pervanadate is known to induce phosphorylation of desmoglein-2 [52], a protein that was stabilized after treatment with this compound [17]). Protein-protein interactions can also be detected with TPP, since stability changes in proteins present in a complex can be identified (for example, kinase complexes containing cyclins were stabilized by the kinase inhibitor staurosporine [15]). To evaluate the function of a protein, the thermal profile of the proteome of cells in which the gene has been knocked-out might offer insight into the mechanism of the protein. The results from TPP could add an interesting layer to knock-out studies, since it is possible to see not only which proteins are stabilized, but also which proteins are destabilized. Destabilization can occur when a protein complex is disturbed or when the concentration of a metabolite is lowered (e.g., panobinostat lowers cholesterol levels and this contributes to a destabilization of apolipoprotein B [16]).

Further, TPP could be combined with other methods that complement protein thermal stability approaches (Fig. 3). For example, a recent study has profiled the melting proteome, in a lysate setting, using limited proteolysis, contributing insight into thermal unfolding at the sequence level [53]. Further understanding of folding and unfolding dynamics might be attained by a combination of single-molecule imaging and thermal stress.

\section{Conclusion}

TPP is a recently developed tool that allows for the study of perturbations on thermal stability of the proteome. This provides information that is complementary to protein expression, since it is influenced by levels of metabolites, post-translational modifications and proteinprotein interactions. TPP has been extensively used for the study of drug targets and off-targets.[19-22, 37-39] However, since this method lies at the interface between proteomics and metabolomics, it has a broad application and can be used to study many fundamental biological questions.

\section{Abbreviations}

2D-TPP: Two-dimensional TPP; CETSA: Cellular thermal shift assay; DARTS: Drug affinity responsive target stability; LiP: Limited proteolysis; 
SPROX: Stability of proteins from rates of oxidation; TILS: Target identification by ligand stabilization; $T_{m}$ : Apparent melting temperature; TMT: Isobaric tandem mass tags; TPP: Thermal proteome profiling; TPP-CCR: Compound concentration range TPP; TPP-TR: Temperature range TPP

\section{Acknowledgements}

We thank Isabelle Becher for the discussions when writing this review.

\section{Funding}

This work was supported by the European Molecular Biology Laboratory.

\section{Availability of data and materials}

not applicable.

\section{Authors' contributions}

All authors wrote the manuscript and approved the final version.

\section{Competing interests}

The authors declare that they have no competing interests.

\section{Consent for publication}

not applicable.

\section{Ethics approval and consent to participate} not applicable.

\section{Publisher's Note}

Springer Nature remains neutral with regard to jurisdictional claims in published maps and institutional affiliations.

\section{Received: 14 April 2017 Accepted: 15 June 2017}

Published online: 24 June 2017

\section{References}

1. Swinney DC, Anthony J. How were new medicines discovered? Nat Rev Drug Discov. 2011;10:507-19.

2. Hughes JP, Rees S, Kalindjian SB, Philpott KL. Principles of early drug discovery. Br J Pharmacol. 2011;162:1239-49.

3. Santos R, Ursu O, Gaulton A, Bento AP, Donadi RS, Bologa CG, Karlsson A, Al-Lazikani B, Hersey A, Oprea TI, Overington JP. A comprehensive map of molecular drug targets. Nat Rev Drug Discov. 2017;16:19-34.

4. Zheng W, Thorne N, McKew JC. Phenotypic screens as a renewed approach for drug discovery. Drug Discov Today. 2013;18:1067-73.

5. Moffat JG, Rudolph J, Bailey D. Phenotypic screening in cancer drug discovery - past, present and future. Nat Rev Drug Discov. 2014;13:588-602.

6. Wagner BK. The resurgence of phenotypic screening in drug discovery and development. Expert Opin Drug Discov. 2016;11:121-5.

7. Schenone M, Dancik V, Wagner BK, Clemons PA. Target identification and mechanism of action in chemical biology and drug discovery. Nat Chem Biol. 2013:9:232-40.

8. Schirle M, Jenkins JL. Identifying compound efficacy targets in phenotypic drug discovery. Drug Discov Today. 2016;21:82-9.

9. Aebersold R, Mann M. Mass-spectrometric exploration of proteome structure and function. Nature. 2016;537:347-55.

10. Li J, Xu H, West GM, Jones LH. Label-free technologies for target identification and validation. Med Chem Commun. 2016;7:769-77.

11. Lomenick B, Hao R, Jonai N, Chin RM, Aghajan M, Warburton S, Wang J, Wu RP, Gomez F, Loo JA, et al. Target identification using drug affinity responsive target stability (DARTS). Proc Natl Acad Sci U S A. 2009;106:21984-9.

12. Strickland EC, Geer MA, Tran DT, Adhikari J, West GM, DeArmond PD, $X u Y$, Fitzgerald MC. Thermodynamic analysis of protein-ligand binding interactions in complex biological mixtures using the stability of proteins from rates of oxidation. Nat Protoc. 2013;8:148-61.

13. West GM, Tang L, Fitzgerald MC. Thermodynamic analysis of protein stability and ligand binding using a chemical modification- and mass spectrometrybased strategy. Anal Chem. 2008;80:4175-85.

14. West GM, Tucker CL, Xu T, Park SK, Han X, Yates 3rd JR, Fitzgerald MC. Quantitative proteomics approach for identifying protein-drug interactions in complex mixtures using protein stability measurements. Proc Natl Acad Sci U S A. 2010;107:9078-82.
15. Savitski MM, Reinhard FB, Franken $H$, Werner T, Savitski MF, Eberhard D, Martinez Molina D, Jafari R, Dovega RB, Klaeger S, et al. Tracking cancer drugs in living cells by thermal profiling of the proteome. Science. 2014:346:1255784.

16. Franken $H$, Mathieson $T$, Childs $D$, Sweetman GM, Werner T, Togel I, Doce C, Gade S, Bantscheff M, Drewes G, et al. Thermal proteome profiling for unbiased identification of direct and indirect drug targets using multiplexed quantitative mass spectrometry. Nat Protoc. 2015;10:1567-93.

17. Reinhard FB, Eberhard D, Werner T, Franken H, Childs D, Doce C, Savitski MF, Huber W, Bantscheff M, Savitski MM, Drewes G. Thermal proteome profiling monitors ligand interactions with cellular membrane proteins. Nat Methods. 2015;12:1129-31.

18. Becher I, Werner T, Doce C, Zaal EA, Togel I, Khan CA, Rueger A, Muelbaier M, Salzer E, Berkers CR, et al. Thermal profiling reveals phenylalanine hydroxylase as an off-target of panobinostat. Nat Chem Biol. 2016;12:908-10.

19. Fontana A, de Laureto PP, Spolaore B, Frare E, Picotti P, Zambonin M. Probing protein structure by limited proteolysis. Acta Biochim Pol. 2004:51:299-321.

20. Kurganov BI, Rafikova ER, Dobrov EN. Kinetics of thermal aggregation of tobacco mosaic virus coat protein. Biochemistry (Mosc). 2002;67:525-33.

21. Asial I, Cheng YX, Engman H, Dollhopf M, Wu B, Nordlund P, Cornvik T. Engineering protein thermostability using a generic activity-independent biophysical screen inside the cell. Nat Commun. 2013;4:2901.

22. O'Sullivan C, Tompson FW. LX.-Invertase: a contribution to the history of an enzyme or unorganised ferment. J Chem Soc Trans. 1890;57:834-931.

23. Schellman JA. Macromolecular binding. Biopolymers. 1975;14:999-1018.

24. Pace CN, McGrath T. Substrate stabilization of lysozyme to thermal and guanidine hydrochloride denaturation. J Biol Chem. 1980;255:3862-5.

25. Vedadi M, Niesen FH, Allali-Hassani A, Fedorov OY, Finerty Jr PJ, Wasney GA, Yeung $R$, Arrowsmith $C$, Ball LJ, Berglund $H$, et al. Chemical screening methods to identify ligands that promote protein stability, protein crystallization, and structure determination. Proc Natl Acad Sci U S A. 2006:103:15835-40.

26. Ericsson UB, Hallberg BM, Detitta GT, Dekker N, Nordlund P. Thermofluorbased high-throughput stability optimization of proteins for structural studies. Anal Biochem. 2006;357:289-98.

27. Pantoliano MW, Petrella EC, Kwasnoski JD, Lobanov VS, Myslik J, Graf E, Carver T, Asel E, Springer BA, Lane P, Salemme FR. High-density miniaturized thermal shift assays as a general strategy for drug discovery. J Biomol Screen. 2001;6:429-40

28. Senisterra GA, Markin E, Yamazaki K, Hui R, Vedadi M, Awrey DE. Screening for ligands using a generic and high-throughput light-scattering-based assay. J Biomol Screen. 2006;11:940-8.

29. Martinez Molina D, Jafari $R$, Ignatushchenko M, Seki T, Larsson EA, Dan C, Sreekumar L, Cao Y, Nordlund P. Monitoring drug target engagement in cells and tissues using the cellular thermal shift assay. Science. 2013;341:84-7

30. Jafari $R$, Almqvist $H$, Axelsson $H$, lgnatushchenko $M$, Lundback $T$, Nordlund $P$, Martinez Molina D. The cellular thermal shift assay for evaluating drug target interactions in cells. Nat Protoc. 2014;9:2100-22.

31. Almqvist $H$, Axelsson $H$, Jafari $R$, Dan C, Mateus A, Haraldsson M, Larsson A, Martinez Molina D, Artursson P, Lundback T, Nordlund P. CETSA screening identifies known and novel thymidylate synthase inhibitors and slow intracellular activation of 5-fluorouracil. Nat Commun. 2016:7:11040.

32. Larance M, Lamond Al. Multidimensional proteomics for cell biology. Nat Rev Mol Cell Biol. 2015;16:269-80.

33. Huber KV, Olek KM, Muller AC, Tan CS, Bennett KL, Colinge J, Superti-Furga G. Proteome-wide drug and metabolite interaction mapping by thermalstability profiling. Nat Methods. 2015;12:1055-7.

34. Vartanian S, Ma TP, Lee J, Haverty PM, Kirkpatrick DS, Yu K, Stokoe D. Application of mass spectrometry profiling to establish brusatol as an inhibitor of global protein synthesis. Mol Cell Proteomics. 2016;15:1220-31.

35. Warpman Berglund U, Sanjiv K, Gad H, Kalderen C, Koolmeister T, Pham T, Gokturk C, Jafari R, Maddalo G, Seashore-Ludlow B, et al. Validation and development of MTH1 inhibitors for treatment of cancer. Ann Oncol. 2016;27:2275-83.

36. Tarasova NK, Gallud A, Ytterberg AJ, Chernobrovkin A, Aranzaes JR, Astruc D, Antipov A, Fedutik Y, Fadeel B, Zubarev RA. Cytotoxic and proinflammatory effects of metal-based nanoparticles on thp-1 monocytes characterized by combined proteomics approaches. J Proteome Res. 2017;16:689-97. 
37. Werner T, Becher I, Sweetman G, Doce C, Savitski MM, Bantscheff M. Highresolution enabled TMT 8-plexing. Anal Chem. 2012;84:7188-94.

38. Werner T, Sweetman G, Savitski MF, Mathieson T, Bantscheff M, Savitski MM. Ion coalescence of neutron encoded TMT 10-plex reporter ions. Anal Chem. 2014;86:3594-601.

39. Sabini E, Ort S, Monnerjahn C, Konrad M, Lavie A. Structure of human dCK suggests strategies to improve anticancer and antiviral therapy. Nat Struct Biol. 2003;10:513-9.

40. Gad H, Koolmeister T, Jemth AS, Eshtad S, Jacques SA, Strom CE, Svensson LM, Schultz N, Lundback T, Einarsdottir BO, et al. MTH1 inhibition eradicates cancer by preventing sanitation of the dNTP pool. Nature. 2014;508:215-21.

41. Dayon L, Hainard A, Licker V, Turck N, Kuhn K, Hochstrasser DF, Burkhard PR, Sanchez JC. Relative quantification of proteins in human cerebrospinal fluids by MS/MS using 6-plex isobaric tags. Anal Chem. 2008;80:2921-31.

42. McAlister GC, Huttlin EL, Haas W, Ting L, Jedrychowski MP, Rogers JC, Kuhn K, Pike I, Grothe RA, Blethrow JD, Gygi SP. Increasing the multiplexing capacity of TMTs using reporter ion isotopologues with isobaric masses. Anal Chem. 2012;84:7469-78.

43. Zubarev RA, Makarov A. Orbitrap mass spectrometry. Anal Chem. 2013:85:5288-96.

44. isobarQuant [https://github.com/protcode/isob].

45. Perkins DN, Pappin DJ, Creasy DM, Cottrell JS. Probability-based protein identification by searching sequence databases using mass spectrometry data. Electrophoresis. 1999;20:3551-67.

46. Cox J, Mann M. MaxQuant enables high peptide identification rates, individualized p.p.b.-range mass accuracies and proteome-wide protein quantification. Nat Biotechnol. 2008;26:1367-72.

47. Tyanova S, Temu T, Cox J. The MaxQuant computational platform for mass spectrometry-based shotgun proteomics. Nat Protoc. 2016;11:2301-19.

48. Bioconductor: Open source software for bioinformatics [http:// bioconductor.org/].

49. TPP: Analyze thermal proteome profiling (TPP) experiments. R package [https://bioconductor.org/packages/release/bioc/html/TPP.html]

50. Peng $H$, Guo $H$, Pogoutse $O$, Wan C, Hu LZ, Ni Z, Emili A. An Unbiased Chemical Proteomics Method Identifies Fabl as the Primary Target of 6OH-BDE-47. Environ Sci Technol. 2016;50(20):11329-36.

51. Kalxdorf M, Gade S, Eberl HC, Bantscheff M. Monitoring Cell-surface N-Glycoproteome Dynamics by Quantitative Proteomics Reveals Mechanistic Insights into Macrophage Differentiation. Mol Cell Proteomics. 2017:16:770-85.

52. Garrod DR, Fisher C, Smith A, Nie Z. Pervanadate stabilizes desmosomes. Cell Adh Migr. 2008;2:161-6.

53. Leuenberger P, Ganscha S, Kahraman A, Cappelletti V, Boersema PJ, von Mering C, Claassen M, Picotti P. Cell-wide analysis of protein thermal unfolding reveals determinants of thermostability. Science. 2017;355(6327):eaai7825.

\section{Submit your next manuscript to BioMed Central and we will help you at every step:}

- We accept pre-submission inquiries

- Our selector tool helps you to find the most relevant journal

- We provide round the clock customer support

- Convenient online submission

- Thorough peer review

- Inclusion in PubMed and all major indexing services

- Maximum visibility for your research

Submit your manuscript at www.biomedcentral.com/submit

) Biomed Central 